\title{
EDITORIAL
}

\section{Métodos y modelos de la investigación anatómica: disecar sin bisturí}

\author{
Gustavo H.R.A. Otegui \\ Centro de Morfología y Neurociencias, C.A.B.A., Departamento de Anatomía, Facultad de Medicina, Universidad de Buenos \\ Aires, Buenos Aires, Argentina \\ Correspondencia: Directorio 962 A, C.A.B.A., Argentina Teléfono: (+54 11) 5950-9500 (interno 2112). Correo electrónico: \\ gotegui@fmed.uba.ar \\ doi: https://doi.org/10.24267/23897325.233
}

La tradición epistémica de la anatomía supone la investigación cadavérica y la disección con bisturí o escalpelo. En este apartado nos proponemos cuestionar este supuesto mostrando evidencia que avala la disección como metodología, pero que esto no supone ni al escalpelo ni al cadáver como métodos excluyentes.

Etimológicamente, la palabra "anatomía" deriva del griego ana: división, y tomé: parte, y "disección" deriva del latín dis: dividir, y sectio: parte. Como puede apreciarse, desde sus orígenes tanto el nombre de la disciplina como su método de investigación encuentran su razón de ser en el reduccionismo metodológico, es decir, dividir, separar, aislar cada uno de los componentes para comprender la estructura, el orden, y la forma de los sistemas y de los subsistemas que estudiamos.

Para ilustrar mi propuesta, mostraré algunos ejemplos históricos que avalan la tesis que sostengo. La cuestión es de suma importancia ya que del paradigma que adoptemos dependerá la originalidad y la relevancia de los problemas de investigación de la anatomía y, por lo tanto, el futuro de esta disciplina como ciencia.

\section{El método anatomo-clínico y la investigación de la anatomía del lenguaje}

Previo a 1861 , se suponía que el cerebro era un todo indivisible, que constituía una unidad anatómica y funcional. Flourens (1) había fundado el holismo basado en experiencias realizadas en modelos animales, en los que seccionaba o extirpaba determinadas partes del animal. En 1861, Broca $(2,3)$ 
descubrió una correlación entre un paciente que sufría afemia (hoy denominada 'afasia'), es decir que no podía emitir un lenguaje articulado, y una lesión en el giro frontal inferior izquierdo. Había llegado la primera demostración científica de que las funciones que cumplía el cerebro tenían una localización precisa. A partir de Broca, se inició el programa de investigación de la anatomía del lenguaje.

En 1874, Wernicke (4) descubrió que las lesiones del sector posterior del giro temporal superior izquierdo causaban afasia sensorial, es decir, incapacidad de comprender lo que alguien está diciendo. Wernicke, propuso el primer modelo conexionista de la anatomía de las funciones cerebrales, al decir que el sistema anatómico que permite el lenguaje articulado está formado por tres componentes: el área de la expresión (Broca), el área de la comprensión (Wernicke) y el fascículo arqueado que conecta ambas áreas.

Al día de hoy, el complejo sistema anatómico que intenta dar cuenta y explicar cómo funciona el lenguaje articulado sigue creciendo en áreas y conexiones, explicando cada vez más funciones y permitiendo comprender las manifestaciones clínicas que sufren los pacientes afectados.

\section{El método electrofisiológico y la investigación de la somatotopía}

En 1950, W. Penfield y T. Rasmussen (5) estimularon la corteza cerebral de pacientes que eran sometidos a cirugía para tratar la epilepsia. Con electrodos de gran precisión, obtuvieron una representación cortical deformada del cuerpo humano. A esta representación deformada del cuerpo humano la denominaron 'homúnculo'. La lengua, la cabeza y el pulgar son enormes cuando se comparan con el espacio que representa al pie. Así, descubrieron que existía una proporcionalidad entre la superficie del área, el número de neuronas y la complejidad funcional. A partir de entonces, múltiples homúnculos se han ido hallando en los distintos órganos del sistema nervioso central (cerebelo, tálamo, etc.).

\section{El método de las secciones o ablaciones y la anatomía de la memoria}

K. S. Lashley, durante casi 20 años (1931 a 1950), había tratado de hallar el área del cerebro donde se localiza la memoria (6-8). Empleando modelos de ratones que aprendían a reconocer un laberinto y usando la lesión por ablación o sección de diferentes sectores encefálicos, intentó demostrar que si se afectaban determinados sitios aparecería la amnesia (incapacidad de formar nuevas memorias) (6-8). 
La conclusión a la que llegó, la plasmó en dos principios a los que denominó: principio de equipotencialidad y principio de acción de masa. El primero sostiene que todo el cerebro tiene el mismo valor para cumplir una función determinada y, el segundo, que la función, y por tanto su déficit, dependen de la cantidad de masa o materia afectada. Como puede verse, con la tesis de Lashley volvemos a defender el holismo del cerebro.

Pocos años después, entre 1955 y 1958, Milner, Scoville y Penfield (9-11) estudiaron un paciente conocido como HM por las iniciales de sus nombres. El paciente sufría de epilepsia y fue tratado por cirugía mediante la exéresis de los sectores mediales del lóbulo temporal. El tratamiento involucró la ablación de parte del hipocampo y de la amígdala. El estudio posquirúrgico reveló que HM podía aprender nuevas tareas y realizaba dibujos cada día con mayor destreza, pero era incapaz de conocer una persona y recordarla al día siguiente o aprender datos referidos a un tema en particular (capitales de países).

Esto reveló que la memoria se basa en un sistema anatómico complejo constituido por diferentes subsistemas, a saber: a) memoria procedimental: existe un subsistema para la memoria de procedimientos y destrezas, habilidades que no dependen del hipocampo sino de los núcleos de la base, del cerebelo y de otras áreas que involucran al movimiento; b) memoria declarativa, compuesta por la memoria semántica y la memoria episódica. La existencia de la memoria declarativa exige la indemnidad del hipocampo, y eso explica por qué, al tenerlo lesionado, HM no podía recordar a las personas que conocía ni aprender datos nuevos.

\section{El método imagenológico}

El estudio de la anatomía por imágenes permite, hoy en día, disecar los componentes que cumplen determinadas funciones. Estos métodos son la resonancia magnética funcional (RMI f), la tomografía por emisión de positrones (PET), la tomografía por emisión de fotón único (SPECT), etc.

Con estos métodos, podemos estudiar en sujetos sanos qué áreas se encienden (están más activas) cuando los pacientes hablan o realizan otras actividades. 
La pronunciación de palabras involucra el área motora primaria; pensar y organizar las frases que van a pronunciarse, requieren del área de Broca; interpretar y decodificar fonológicamente lo que el sujeto escucha, involucran el área de Wernicke, y finalmente, la semántica del lenguaje depende del área de Geschwind (giro angular) (12).

A manera de apretada síntesis, hemos presentado cuatro métodos y modelos de investigación que han contribuido a formular problemas científicos originales y relevantes. Las interpretaciones de los resultados obtenidos contribuyeron significativamente al avance de la comprensión anatómica de cada una de las regiones estudiadas.

Esta evidencia, a mi modo de ver, demuestra de forma categórica, que el reduccionismo metodológico (disección) contribuye a entender la estructura constitutiva del sistema anatómico estudiado, y el ¿emergentismo? aplicado a la composición e integración posterior de cada uno de los componentes descubiertos es capaz de descubrir la función derivada (emergente) del sistema estudiado. Ambos (reduccionismo y iemergentismo?) constituyen el paradigma que ilumina el camino de la anatomía del futuro.

\section{REFERENCIAS}

1. Flourens MJP. Recherches expèrimentales sur les propriétés et les fonctions du système nerveux dans le animaux vertébrés. Paris: Crevot; 1824.

2. Broca P. Remarques sur la siege de la faculte du langage articulé, suivies d'une observation du aphemie. Bulletin Societe de Anatomie. 1861; 36: 330-357.

3. Broca P. Localisation des fonctions cerebrals. Siège du language articulé. Bull Soc Anthrop. 1863. 4: 200-202.
4. Wernicke C. Der aphasische Symptomen Komplex. Breslau: Franck y Weigert; 1878.

5. Penfield W, Rasmussen T. The Cerebral Cortex of Man. New York: Macmillan; 1950.

6. Lashley KS. Mass action in cerebral function. Science. 1931; 73 (1888): 245-254.

7. Lashley KS. Functional determinants of cerebral localization. Arch Neur Psych. 1937; 38 (2): 371-387. 
8. Lashley KS. In search of the engram. Society for Experimental Biology. Symposium. 1950; 4: 454-482.

9. Milner B, Penfield W. The effect of hippocampal lesions on recent memory. Trans. Am Neurol Assoc 80th Meeting. 1955; 42-48.

10. Scoville WB, Milner B. Loss of recent memory after bilateral hipocampal lesions. J. Neurol Neurosurg Psychiatry. 1957; 20: 11-21.
11. Penfield W, Milner, B. Memory deficit produced by bilateral lesions in the hippocampal zone. A.M.A. archives of neurology and psychiatry. 1958; 79 (5): 475-497

12. Catani M, Jones DK, Ffytche DH. Perisylvian Language Networks of the Human Brain. Ann Neurol. 2005; 57: 8-16

Esta obra está bajo una licencia de Creative Commons Reconocimiento-NoComercial 4.0 Internacional 